UPPSALA UNIVERSITET
Working Paper 2006:31

Department of Economics

\title{
Monetary Policy and Staggered Wage Bargaining when Prices are Sticky
}

Mikael Carlsson and Andreas Westermark 
Department of Economics

Uppsala University

P.O. Box 513

SE-751 20 Uppsala

Sweden

Fax: +46184711478
Working paper 2006:31

December 2006

ISSN 1653-6975

Monetary Policy and Staggered Wage Bargaining when Prices are Sticky

Mikael Carlsson and Andreas Westermark

Papers in the Working Paper Series are published on internet in PDF formats.

Download from http://www.nek.uu.se

or from S-WoPEC http://swopec.hhs.se/uunewp/ 


\title{
Monetary Policy and Staggered Wage Bargaining when Prices are Sticky*
}

\author{
Mikael Carlsson ${ }^{\dagger}$ and Andreas Westermark ${ }^{\ddagger}$
}

January 11, 2007

\begin{abstract}
In this paper, we outline a baseline DSGE model which enables a straightforward analysis of wage bargaining between firms and households/unions in a model with both staggered prices and wages. Relying on empirical evidence, we assume that prices can be changed whenever wages are changed. This feature of the model greatly reduces the complexity of the price and wage setting decisions; specifically it removes complicated interdependencies between current and future price and wage decisions. In an application of the model we study the interaction between labor-market institutions and monetary policy choices, and the consequences for welfare outcomes. Specifically, we focus on the relative bargaining power of unions. We find that, for a standard specification of the monetary policy rule, welfare is substantially affected by the degree of relative bargaining power, but that this effect can be neutralized by optimal discretionary policy.
\end{abstract}

Keywords: Monetary Policy, Labor Market, Bargaining.

JEL classification: E52, E58, J41.

\footnotetext{
${ }^{*}$ We are grateful for comments and suggestions from Jesper Lindé, Karl Walentin and seminar participants at Uppsala University and Sveriges Riksbank. Carlsson gratefully acknowledges financial support from Jan Wallander's and Tom Hedelius' Research Foundation and Westermark from the Swedish Council for Working Life and Social Research. The views expressed in this paper are solely the responsibility of the authors and should not be interpreted as reflecting the views of the Executive Board of Sveriges Riksbank.

${ }^{\dagger}$ Research Department, Sveriges Riksbank, SE-103 37, Stockholm, Sweden. e-mail: mikael.carlsson@riksbank.se.

${ }^{\ddagger}$ Department of Economics, Uppsala University, P.O. Box 513, SE-751 20 Uppsala, Sweden. e-mail: andreas.westermark@nek.uu.se.
} 


\section{Introduction}

The interrelationship between monetary policy and labor-market institutions has been widely discussed, see e.g. Calmfors (2001) and references therein. The focus of this literature has usually been on monetary policy, labor market reform and the effects on the equilibrium unemployment rate. In contrast, there has been less work regarding the effects on equilibrium dynamics of labor-market institutions and the scope for stabilization policy.

Models of the labor market have recently been incorporated in New Keynesian DSGE models. The seminal paper by Erceg, Henderson, and Levin (2000) outlines a model with both staggered prices and wages. However, in Erceg, Henderson, and Levin (2000), wages are solely determined by households/unions. To introduce both staggered prices and wages when wages are bargained over is complicated, since there will be a dependence between current and future price/wage setting, when relying on staggered Calvo contracts. Specifically, this is due to the fact that prices in a firm affect firm profits which, in turn, affect the bargained wage. Then, since wages in turn affect marginal costs, there will be a link between current and future price decisions. Thus, under wage bargaining, price and, by a similar argument, wage decisions cannot be analyzed by the simple methods in the standard Calvo framework, where current decisions are independent of future and past decisions.

The purpose of this paper is to outline a baseline model that allows us to easily study wage bargaining between unions and firms in a model with both staggered prices and wages. In an application of the model, we study the interaction between labor market institutions and monetary policy choices, and the consequences for equilibrium dynamics and welfare outcomes. Specifically, we focus on the bargaining power of unions.

In the model, price and wage setting are staggered. The main difference with our approach, relative to standard DSGE models based on Erceg, Henderson, and Levin (2000) that includes a labor market (see e.g. Christiano, Eichenbaum, and Evans (2005), Smets and Wouters (2003) and Adolfson, Laséen, Lindé, and Villani (2005)), is that we model wages as being determined in bargaining between firms and unions (households). For this purpose, we must modify the simplifying assumption of Erceg, Henderson, and Levin (2000) that workers work at all firms. Otherwise, each worker works an infinitesimal amount at each firm, implying that the effect of the worker on the firm surplus is zero and that there is no surplus to be negotiated over, hence rendering bargaining irrelevant. Note that this is actually the way the dependency problem discussed above is solved in the Erceg, Henderson, and Levin (2000) model, since the price in a given firm does not affect the wage choice in a household and vice versa. Instead, we assume that a worker works at a specific firm, generating the dependency problem discussed above. However, we show that these problems can be solved in a straightforward fashion by slightly modifying the standard Calvo contracts. As in Calvo (1983), firms are allowed to change prices 
in a given period with some fixed probability. Moreover, wage bargaining is opened with some fixed probability in each period. We modify the standard Calvo setup by letting any firm that is allowed to change wages, to also change prices. This assumption is in line with the micro evidence presented in Altissimo, Ehrmann, and Smets (2006), where price and wage changes seem to be synchronized. ${ }^{1}$ The key aspect of this assumption is that it greatly simplifies our problem; especially it eliminates the interdependence between current and future prices. Similarly, the interdependence between current and future wage contracts is eliminated.

We show that the wage setting relationship is similar, but not identical to the condition derived in Erceg, Henderson, and Levin (2000). The differences are due, first, to the fact that today's wage contract affects the price set today by the firm and, second, to the fact that wages are determined in bargaining between firms and workers and thus, are not set unilaterally by workers. In general, we can write the wage setting relationship as a convex combination of the wage setting relationships when wages are set unilaterally by the firm and the household/union, respectively.

The main result from our application of the model is that welfare under a Taylor rule decreases significantly when the bargaining power of unions increases. The reason for this result is that the stronger is the union in the bargaining process, the larger are the effects on wage outcomes from changes in the total surplus, since an increase in the total surplus in the negotiation leads to a larger wage increase, and hence larger wage inflation variability, when the union has more bargaining power. ${ }^{2}$ Thus, the more will wages fluctuate in response to disturbances, leading to a decrease in welfare. Under an optimal discretionary policy on the other hand, this effect is neutralized by the central bank.

In sections 2, 3 and 4, we outline the model, describe the market clearing conditions and derive a quadratic expression for the social welfare function, respectively. In section 5 , we discuss the implementation of a Taylor rule as well as characterize optimal discretionary monetary policy. Sections 6 and 7 discuss the baseline calibration and our results, respectively. Finally, section 8 concludes.

\section{The Economic Environment}

The model outlined below is in many respects similar to the model in Erceg, Henderson, and Levin (2000). Goods are produced by monopolistically competitive producers using capital and labor. Producers set prices in staggered contracts as in Calvo (1983). There are also some important differences,

\footnotetext{
${ }^{1}$ Here, we assume that wage changes induce price changes, since assuming the reverse would imply that the duration of wage contracts could never be longer than for prices, which do not seem to be the case empirically, see section 6 .

${ }^{2}$ Since all surplus is transferred to households either via wages or dividends from firms, this implies that transfers from dividends decrease when bargaining power increases.
} 
however. In contrast to Erceg, Henderson, and Levin (2000), a household is attached to each firm. ${ }^{3,4}$ Thus, firms do not perceive workers as atomistic. In each period, bargaining over wages takes place with a fixed probability. Accordingly, wages are staggered as in Calvo (1983) but, in contrast to Erceg, Henderson, and Levin (2000), they are determined in bargaining between the union and the firm. Households derive utility from consumption, real balances and leisure, earning income by working at firms and from capital holdings. Below, we present the model in more detail and derive key relationships (for a full derivation, see the Technical Appendix in Carlsson and Westermark (2006)).

\subsection{Firms and price setting}

Since households will be identical, except for leisure choices, it simplifies the analysis to abstract away from the households' optimal choices for individual goods. Thus, we follow Erceg, Henderson, and Levin (2000) and assume a competitive sector selling a composite final good. The composite good is combined from individual or intermediate goods in the same proportions as those that households would choose. The composite good is

$$
Y_{t}=\left[\int_{0}^{1} Y_{t}(f)^{\frac{\sigma-1}{\sigma}}\right]^{\frac{\sigma}{\sigma-1}}
$$

where $\sigma>1$ and $Y_{t}(f)$ is the intermediate good produced by firm $f$. The price $P_{t}$ of one unit of the composite good is set equal to the marginal cost

$$
P_{t}=\left[\int_{0}^{1} P_{t}(f)^{1-\sigma} d f\right]^{\frac{1}{1-\sigma}}
$$

By standard arguments, the demand function for the intermediate good $f$, is

$$
Y_{t}(f)=\left(\frac{P_{t}(f)}{P_{t}}\right)^{-\sigma} Y_{t}
$$

The production of firm $f$ in period $t, Y_{t}(f)$, is given by the following constant returns technology

$$
Y_{t}(f)=A_{t} K_{t}(f)^{\gamma} L_{t}(f)^{1-\gamma}
$$

where $A_{t}$ is the technology level common to all firms and $K_{t}(f)$ and $L_{t}(f)$ denote the firms' capital and labor input in period $t$, respectively. Since firms have the right to manage, $K_{t}(f)$ and $L_{t}(f)$ are

\footnotetext{
${ }^{3}$ Several households could be attached to a firm, if these negotiate together.

${ }^{4}$ There is no reallocation of workers among firms. This is obviously a simplifying assumption, but it enables us to describe the model in terms of very simple relationships.
} 
chosen optimally, taking the rental cost of capital and the bargained wage $W_{t}(f)$ as given. Moreover, as in Erceg, Henderson, and Levin (2000), the aggregate capital stock is fixed at $\bar{K}$. Standard costminimization arguments then imply that the marginal cost in production is given by ${ }^{5}$

$$
M C_{t}(f)=\frac{W_{t}(f)}{M P L_{t}(f)}
$$

where $M P L_{t}(f)$ is the firm marginal product of labor.

\subsubsection{Prices}

The firm is allowed to change prices in a given period with probability $1-\alpha$ and renegotiate wages with probability $1-\alpha_{w}$. Any firm that is allowed to change wages is also allowed to change prices. Thus, the probability that a firm's price is unchanged is $\alpha_{w} \alpha$. The latter assumption greatly simplifies our problem; in particular it eliminates any intertemporal interdependence between current and future price decisions via its effect on wage contracts for a given firm (see section 2.3 below). Moreover, it is also in line with the micro-evidence on price-setting behavior presented in Altissimo, Ehrmann, and Smets (2006), where price and wage changes seem to be synchronized (see especially their figure 4.4). Here, we assume that wage changes induce price changes, since assuming the reverse would imply that the duration of wage contracts could never be longer than for prices, which seems empirically implausible, see section 6. Furthermore, since intertemporal interdependencies are eliminated, this allows us to describe the goods market equilibrium by a similar type of forward looking new Keynesian Phillips curve as in Erceg, Henderson, and Levin (2000); see (17).

The producers choose prices to maximize

$$
\begin{aligned}
& \max _{p_{t}(f)} E_{t} \sum_{k=0}^{\infty}\left(\alpha_{w} \alpha\right)^{k} \Psi_{t, t+k}\left[(1+\tau) P_{t}(f) Y_{t+k}(f)-T C\left(W_{t+k}(f), Y_{t+k}(f)\right)\right] \\
\text { s. t. } Y_{t+k}(f)= & \left(\frac{P_{t}(f)}{P_{t+k}}\right)^{-\sigma} Y_{t+k},
\end{aligned}
$$

where $T C\left(W_{t+k}(f), y_{t+k}(f)\right)$ denotes the cost function, $\Psi_{t+k}$ is the households' valuation of nominal profits in period $t+k$ when in period $t$ and $\tau$ is a tax/subsidy on output. The term inside the square brackets is just firm profits in period $t+k$, given that prices are last reset in period $t$. The first-order condition is

$$
E_{t} \sum_{k=0}^{\infty}\left(\alpha_{w} \alpha\right)^{k} \Psi_{t, t+k}\left[\frac{\sigma-1}{\sigma}(1+\tau) P_{t}(f)-M C_{t+k}(f)\right] Y_{t+k}(f)=0
$$

\footnotetext{
${ }^{5}$ In contrast to Erceg, Henderson, and Levin (2000), the marginal cost is not generally equal among firms, since firms face different wages out of steady state.
} 
The subsidy $\tau$ is determined so as to set $\frac{\sigma-1}{\sigma}(1+\tau)=1$. That is, we assume that fiscal policy is used to alleviate distortions due to monopoly price setting. Thus, here we abstract from any Barro-Gordon type of credibility problems (see Barro and Gordon (1983a) and Barro and Gordon (1983b)).

\subsection{Households}

The economy is populated by a continuum of households, also indexed on the unit interval, which each supplies labor to a single firm. This setup can also be interpreted as a unionized economy. In such a framework, each household can be considered as the representative union member.

The expected life time utility of the household working at firm $f$ in period $t$, is given by ${ }^{6}$

$$
E_{t}\left\{\sum_{s=t}^{\infty} \beta^{s-t}\left[u\left(C_{s}(f)\right)+l\left(\frac{M_{s}(f)}{P_{s}}\right)-v\left(L_{s}(f)\right)\right]\right\}
$$

where period $s$ utility is additively separable in three arguments, final goods consumption $C_{s}(f)$, real money balances $\frac{M_{s}(f)}{P_{s}}$, where $M_{s}(f)$ denotes money holdings, and the disutility of working $L_{s}(f)$. Finally, $\beta \in(0,1)$ is the household's discount factor.

The budget constraint of the household is

$$
\frac{\delta_{t+1, t} B_{t}(f)}{P_{t}}+\frac{M_{t}(f)}{P_{t}}+C_{t}(f)=\frac{M_{t-1}(f)+B_{t-1}(f)}{P_{t}}+\left(1+\tau_{w}\right) \frac{W_{t}(f) L_{t}(f)}{P_{t}}+\frac{\Gamma_{t}}{P_{t}}+\frac{T_{t}}{P_{t}}
$$

The term $\delta_{t+1, t}$ represents the price vector of assets that pays one unit of currency in a particular state of nature in the subsequent period, while the corresponding elements in $B_{t}(f)$ represent the quantity of such claims bought by the household. Moreover, $B_{t-1}(f)$ is the realization of such claims bought in the previous period. $W_{t}(f)$ denotes the household's nominal wage and $\tau_{w}$ is the tax/subsidy on labor income. Each household owns an equal share of all firms and the aggregate capital stock. Then, $\Gamma_{t}$ is the household's aliquot share of profits and rental income. Finally, $T_{t}$ denotes nominal lump-sum transfers from the government. As in Erceg, Henderson, and Levin (2000), we assume that there exist complete contingent claims markets (except for leisure) and equal initial wealth across households. Then, households are homogeneous with respect to consumption and money holdings, i.e., we have $C_{t}(f)=C_{t}$, and $M_{t}(f)=M_{t}$ for all $t$.

\footnotetext{
${ }^{6}$ In the Technical Appendix, we also introduce a consumption shock and a labor-supply shock as in Erceg, Henderson, and Levin (2000). However, introducing these shocks does not yield any additional insights here. In fact, it can easily be shown that under optimal policy, all disturbances in the model (introduced as in Erceg, Henderson, and Levin (2000)) can be reduced to a single disturbance term (being a linear combination of all these shocks).
} 


\subsection{Wage setting}

The wage is determined in bargaining between the firm and the household. For bargaining to make sense, we must relax the assumption made in Erceg, Henderson, and Levin (2000) that a household works an infinitesimal amount at all firms. This assumption implies that when a household negotiates the wage with a firm, there is no surplus to be negotiated over. For a surplus to exist, the working time at a firm must be bounded away from zero. We assume that workers are attached to a specific firm and only work at that firm.

Note that this assumption implies that there is interdependence between wage and price choices. The reason is that the firm price affects both firm profits and labor demand and hence, worker payoff. This, in turn, affects the bargained wage. Specifically, an important implication of this is that there is a potential relationship between wage negotiations today and in the future. The reason is that the wage set today affects prices set in the future which, in turn, act as a state variable in future wage negotiations. Similarly, there is a potential relationship between current and future price setting through wages. Such interdependence would make the analysis of wages and prices much more complicated.

These interdependencies are not present in e.g. Erceg, Henderson, and Levin (2000), where households work an infinitesimal amount in each firm and hence are unaffected by price decisions in individual firms, implying that local prices do not affect wage decisions. Moreover, individual wages in a specific household do not affect price setting in firms by a similar argument.

Importantly, the assumption that whenever wages are changed, prices are also adjusted alleviates the interdependency problem in our model. Specifically, it ensures that there is no interdependence between current and future wage setting, since the only channel that could cause this - a price that is valid for two different wage contracts - is ruled out. Although intertemporal interdependencies are eliminated, we still need to keep in mind that the current wage contract affects current and future price decisions.

\subsubsection{Wage determination}

To state household/union utility during a wage contract renegotiated in period $t$, denoted $U_{u}^{t}$, we define per period utility as

$$
\Upsilon_{t, t+k}(W(f))=u\left(C_{t+k}\right)-v\left(L_{t, t+k}(f)\right)
$$

where $L_{t, t+k}(f)$ denotes labor demand in period $t+k$, when prices were last reset in period $t$. Below, we use superscripts to indicate the last time a wage contract was rewritten and subscripts to indicate 
when a price was last changed. Household utility $U_{u}^{t}$ is then

$$
U_{u}^{t}=E_{t} \sum_{k=0}^{\infty}\left(\alpha_{w} \alpha \beta\right)^{k} \Upsilon_{t, t+k}(W(f))+E_{t} \sum_{k=1}^{\infty}\left(\alpha_{w} \beta\right)^{k}(1-\alpha) \sum_{j=0}^{\infty}\left(\alpha_{w} \alpha \beta\right)^{j} \Upsilon_{t+k, t+k+j}(W(f))
$$

The first sum collects the terms when prices do not change in the future. The last sum collects the terms when prices but not wages are changed at least once in the future. ${ }^{7}$

Denote real per-period profits in period $t+k$, when the price $P_{t}^{o}(f)$ was reset in period $t$, as

$$
\phi_{t, t+k}(W(f))=(1+\tau) \frac{P_{t}^{o}(f)}{P_{t+k}} Y_{t+k}(f)-t c\left(\frac{W(f)}{P_{t+k}}, p_{t+k}^{c}, Y_{t+k}(f)\right),
$$

where $t c$ denotes real total cost. Firm payoff $U_{f}^{t}$ is

$$
\begin{aligned}
U_{f}^{t}= & E_{t} \sum_{k=0}^{\infty}\left(\alpha_{w} \alpha\right)^{k} \psi_{t, t+k} \phi_{t, t+k}(W(f)) \\
& +E_{t} \sum_{k=1}^{\infty}\left(\alpha_{w}\right)^{k}(1-\alpha) \sum_{j=0}^{\infty}\left(\alpha_{w} \alpha\right)^{j} \psi_{t, t+k+j} \phi_{t+k, t+k+j}(W(f)) .
\end{aligned}
$$

The first summation collects the terms where the firm changes prices today and is not selected to change prices in the future. The second summation collects the terms where the firm changes prices in the future at least once. The term $\psi_{t, t+k}$ is how the households value real profits in period $t+k$ when in period $t$ (see the Technical Appendix or Erceg, Henderson, and Levin (2000) for a definition).

We think of bargaining as non-cooperative (see Rubinstein (1982)). However, relying on the equivalence result in Rubinstein (1982) between non-cooperative bargaining and the Nash bargaining solution, we solve for the wage from the Nash bargaining solution

$$
\max _{W(f)}\left(U_{u}^{t}-U_{o}\right)^{\varphi}\left(U_{f}^{t}\right)^{1-\varphi}
$$

where $\varphi$ is the relative bargaining power of the household and $U_{o}$ is the threat point for the household. The threat point is the payoff when there is disagreement (i.e., strike or lockout). The payoff of the

\footnotetext{
${ }^{7}$ Expression (11) is the utility of the current wage contract only. Total utility is$$
E_{t} \sum_{k=0}^{\infty}\left(\alpha_{w} \alpha \beta\right)^{k} \Upsilon_{t, t+k}(W(f))+E_{t} \sum_{k=1}^{\infty}\left(\alpha_{w} \beta\right)^{k}(1-\alpha) \sum_{j=0}^{\infty}\left(\alpha_{w} \alpha \beta\right)^{j} \Upsilon_{t+k, t+k+j}(W(f))
$$$$
+\left(1-\alpha_{w}\right) \sum_{i=1}^{\infty} \beta U_{u}^{t+i}
$$

However, since the household is attached to firm $f$, the terms $\left(1-\alpha_{w}\right) \sum_{i=1}^{\infty} \beta U_{u}^{t+i}$ are also included in the threat point defined below. Hence, since the conflict takes place under the current contract and behavior when new contract negotiations are initiated is expected to follow equilibrium behavior, it suffices to look at the difference between the current contract and the threat point, since all future terms $U_{u}^{t+i}$ cancel. 
firm when there is a disagreement is assumed to be zero. Households are assumed to receive a share of steady-state (after tax) income and not spend any time working. This interpretation of threat points is in line with a standard Rubinstein-Ståhl bargaining model with discounting and no risk of breakdown as presented in Binmore, Rubinstein, and Wolinsky (1986) (see also Mortensen (2005) for an application of this bargaining setup). A constant $U_{o}$ is important for our results. This leads to a very convenient and simple analysis; more complicated models of threat points, e.g. based on workers having the opportunity to search for another job, could also be introduced in this model. However, to keep the model as simple as possible, we leave this to future research.

The first-order condition to (14) is

$$
\varphi U_{f}^{t} \frac{\partial U_{u}^{t}}{\partial W(f)}+(1-\varphi)\left(U_{u}^{t}-U_{o}\right) \frac{\partial U_{f}^{t}}{\partial W(f)}=0
$$

In Erceg, Henderson, and Levin (2000), $\tau_{w}$ is used to eliminate distortions in wage setting. Here, both $\tau_{w}$ and $U_{o}$ can be adjusted to achieve efficiency. As discussed below, adjusting $\tau_{w}$ as in Erceg, Henderson, and Levin (2000) is not a viable option, since this approach leads to inconsistencies when $\varphi<1$ (see section 3.1 below). Then, we must use both $\tau_{w}$ and $U_{o}$ to eliminate distortions on the labor market. Then, there is a continuum of possible ways of ensuring efficiency, all leading to different wage setting behavior. The way we pin down a unique wage-setting curve is to adjust both $\tau_{w}$ and $U_{o}$ such that each party's share of the total surplus corresponds to its relative bargaining power. This is how the surplus is divided in linear bargaining problems, see Osborne and Rubinstein (1990). We outline how this is done in the Technical Appendix. ${ }^{8}$ Then, we eliminate the two distortions in the economy stemming from monopoly power in the intermediate goods market and from household bargaining power in the labor market by using $\tau$ and $U_{o}$.

\subsection{Steady state}

In the zero-inflation non-stochastic steady state, $A_{t}$ is equal to its steady-state value, $\bar{A}$. Moreover, all firms produce the same (constant) amount of output, i.e. $\bar{Y}(f)=\bar{Y}$, using the same (constant) quantity of labor and all households supply the same amount of labor, i.e. $\bar{L}(f)=\bar{L}$. Moreover, we will have that $\bar{C}=\bar{Y}$ and that $B=0 . M$ and $P$ are constant.

To find the steady state of the model, we use the production function (4) together with the efficiency condition $\overline{M P L}=\overline{M R S}$ (which holds due to our having eliminated distortions as outlined above) to solve for $\bar{L}$ and, in turn, $\bar{Y}$ and $\bar{C}$.

\footnotetext{
${ }^{8}$ Specifically, we locally approximate the bargaining problem above with a linear bargaining problem to solve for $U_{o}$. Then, it is shown that this approach implies that $\tau_{w}=0$.
} 


\section{Market Equilibrium Conditions}

Since we eliminate the distortions in the economy (using $\tau$ and $U_{0}$ ), it follows that it then suffices to look at a linear-quadratic representation of the model to rank policies in terms of welfare (see Woodford (2003) ch. 6 for a discussion). Then, we proceed by log-linearizing the first-order conditions describing market behavior. First, let the superscript * denote variables in the flexible price and wage equilibrium, which we below refer to as the natural equilibrium, and a hat above a small letter variable denotes log-deviations from the variables steady-state level (except the output gap, $\hat{x}$, which is defined as the log-deviation between output and the natural output level). Linearizing around the steady state then gives the following system of equations

$$
\begin{aligned}
& \hat{x}_{t}=E_{t}\left(\hat{x}_{t+1}-\frac{1}{\rho_{C}}\left(\hat{i}_{t}-\hat{\pi}_{t+1}-\hat{r}_{t}^{*}\right)\right) \\
& \hat{\pi}_{t}=\beta E_{t} \hat{\pi}_{t+1}+(1-\gamma)\left(\hat{\pi}_{t}^{\omega}-\beta E_{t} \hat{\pi}_{t+1}^{\omega}\right)+\Pi\left(\hat{w}_{t}-\hat{w}_{t}^{*}\right)+\frac{\gamma}{1-\gamma} \Pi \hat{x}_{t}, \\
& \hat{w}_{t}=\hat{w}_{t-1}+\hat{\pi}_{t}^{\omega}-\hat{\pi}_{t},
\end{aligned}
$$

where $1 / \rho_{c}$ is the intertemporal elasticity of substitution in consumption and

$$
\Pi=\left(1-\alpha_{w} \alpha \beta\right) \frac{1-\alpha_{w} \alpha}{\alpha_{w} \alpha}
$$

Equation (16) is the goods demand equation which relates the output gap $\hat{x}_{t}$ to the expected future output gap and the expected real interest rate gap $\left(\widehat{i}_{t}-\hat{\pi}_{t+1}-\widehat{r}_{t}^{*}\right)$, where $\widehat{i}_{t}$ denotes the log-deviation of the nominal interest rate from steady state and $\widehat{r}_{t}^{*}$ is the log-deviation of the natural real interest rate from its steady state. This relation is derived using the household's first-order condition with respect to consumption, i.e., the consumption Euler equation (see the Technical Appendix for details).

The price setting (Phillips) curve, equation (17) is derived from the firms' first-order condition (7), (see the Technical Appendix for details). To better understand the price setting curve we can rewrite (17) as

$$
\hat{\pi}_{t}=\beta E_{t} \hat{\pi}_{t+1}+(1-\gamma)\left(\hat{\pi}_{t}^{\omega}-\beta E_{t} \hat{\pi}_{t+1}^{\omega}\right)+\Pi\left(\hat{w}_{t}-\widehat{m p l}_{t}\right) .
$$

Standard arguments imply that increases in real marginal costs (i.e., $\hat{w}_{t}-\widehat{m p l}_{t}$ ) lead to an increase in prices. In our model, the real wage driving inflation is different from the economywide average $\hat{w}_{t}$. The reason is that there is a dependence between the probability of changing the price and whether the wage changes in the current period or not. Specifically, since all firms that are allowed to change wages are also allowed to change prices, the share of wage-changing firms among the firms that 
change prices is different from the economywide average, which then motivates the "correction term" $(1-\gamma)\left(\hat{\pi}_{t}^{\omega}-\beta E_{t} \hat{\pi}_{t+1}^{\omega}\right)$, where the real wage change in firms that change prices has been decomposed into the aggregate real wage change $\hat{w}_{t}$ and a wage inflation term $\hat{\pi}_{t}^{\omega}$.

The evolution for the real wage follows from the definition of the aggregate real wage and is described by the identity (18), which states that today's real wage is equal to yesterday's real wage plus the difference between wage and price changes $\left(\hat{\pi}_{t}^{\omega}-\hat{\pi}_{t}\right)$.

The wage setting behavior is described by the following equation

$$
\hat{\pi}_{t}^{\omega}=\beta E_{t} \hat{\pi}_{t+1}^{\omega}-\Pi_{1} \Omega_{w}\left(\hat{w}_{t}-\hat{w}_{t}^{*}\right)-\Pi_{1} \Omega_{x} \hat{x}_{t}
$$

where

$$
\Pi_{1}=\left(1-\alpha_{w} \beta\right) \frac{1-\alpha_{w}}{\alpha_{w}},
$$

and $\Omega_{w}$ and $\Omega_{x}$ are complicated functions of the household's relative bargaining power and other deep parameters (see the Technical Appendix for details).

To understand wage setting, it is convenient to first rewrite (21) in terms of deviations of wages from the marginal rate of substitution and the marginal product of labor, respectively. We have

$$
\begin{aligned}
\hat{\pi}_{t}^{\omega}= & \beta E_{t} \hat{\pi}_{t+1}^{\omega}-(1-\varphi) \frac{\Pi_{1}}{\kappa} \sigma\left(\hat{w}_{t}-\widehat{m p l}_{t}\right) \\
& -\varphi \frac{\Pi_{1}}{\kappa}\left(\left(\hat{w}_{t}-\widehat{m r}_{t}\right)-\left(\rho_{L} \sigma+(1-\sigma)\right)\left(\hat{w}_{t}-\widehat{m p l}_{t}\right)+\left(\rho_{C}-1\right) \hat{x}_{t}\right),
\end{aligned}
$$

where $\kappa=-\left(\varphi\left(\frac{\varepsilon_{L}}{1+\varepsilon_{L}}\left(1+\rho_{L} \varepsilon_{L}\right)+1\right)-(1-\varphi) \varepsilon_{L}\right), \varepsilon_{L}=-(\gamma+\sigma(1-\gamma))$ is labor demand elasticity with respect to the wage and $\frac{1}{\rho_{L}}$ is the intertemporal elasticity of substitution in labor. Note that $\kappa>0$. The above expression can be viewed as a convex combination of the first-order condition when wages are unilaterally set by either the firm or the worker. ${ }^{9}$ The last term on the right-hand side comes from the first-order condition when workers have all bargaining power and the second term from the first-order condition when the firm has all bargaining power. ${ }^{10}$

\footnotetext{
${ }^{9}$ To see this, multiply the expression by $\kappa$, rearrange and use the results in the Technical Appendix.

${ }^{10}$ When the worker has all bargaining power, the wage is determined by $\frac{\partial U_{u}^{t}}{\partial W(f)}=0$. To derive this, solve

$$
\max U_{u}^{t}
$$

subject to

$$
U_{f}^{t} \geq 0
$$

The first-order condition is in general$$
\frac{\partial U_{u}^{t}}{\partial W(f)}-\lambda \frac{\partial U_{f}^{t}}{\partial W(f)}=0
$$

where $\lambda$ is the Lagrange multiplier for the constraint. Note that $\lambda$ is nonzero only if the constraint binds. Since firms receive a strictly positive steady-state profit (i.e., $\tau \bar{Y}$ ), this is not the case here and hence $\frac{\partial U_{u}^{t}}{\partial W(f)}=0$. When the firm has all bargaining power, the wage is similarly determined. However, as $\varphi$ tends to zero, the threat point of workers
} 
Suppose $\varphi=1$ in (23), thus corresponding to the case when the households set wages unilaterally. Then, only the first and last terms in (23) remain. Let us first look at the terms involving deviations of real wages from the marginal rate of substitution and the marginal product, respectively. First, there is a direct effect through the consumption-leisure choice of households. If the real wage is larger than the marginal rate of substitution between leisure and consumption, workers desire lower wages to adjust this misalignment, leading to a decrease in wage inflation pressure since wage-changing unions decrease wages. Second, if $\hat{w}_{t}>\widehat{m p l}_{t}$, the marginal costs are high. Then, a reduction in wages increases the surplus, inducing wage-changing unions to cut wages. Finally, the effect through the output gap is due to the fact that a change in the output gap changes how wage increases affect consumption and, in turn, the utility of a wage increase. First, an increase in the output gap reduces the marginal utility of consumption and hence, a given wage increase is worth less in utility terms, leading to a reduction in wages. Second, an increase in the output gap increases labor demand and hence, a given wage increase leads to a larger effect on consumption, and is thus worth more for the household (for a constant marginal utility), leading to an increase in wages. In our baseline calibration, $\rho_{C}>1$, thus implying that the effect from marginal utility of consumption dominates.

When $\varphi=0$, i.e., when firms set wages unilaterally, only the first and second terms in (23) remain. When $\hat{w}_{t}>\widehat{m p l}_{t}$, firms reduce production and hence labor input. Since leisure increases utility, firms can then decrease wages so that the participation constraint of the workers binds. ${ }^{11}$

\subsection{Comparison with Erceg, Henderson, and Levin (2000)}

Erceg, Henderson, and Levin (2000) derive the following wage setting curve

$$
\hat{\pi}_{t}^{\omega}=\beta E_{t} \hat{\pi}_{t+1}^{\omega}-\frac{\Pi_{1}}{1+\varepsilon_{L} \rho_{L}}\left(\hat{w}_{t}-\widehat{m r} s_{t}\right)
$$

A crucial assumption underlying this expression is that the wage subsidy $\tau_{w}$ is set such that it eliminates the markup in wage setting. We choose a different method when deriving (23), as motivated below. When workers have all bargaining power (i.e. $\varphi=1$ ), we can set taxes in the same way in Erceg, Henderson, and Levin (2000). The resulting wage equation is then

$$
\hat{\pi}_{t}^{\omega}=\beta E_{t} \hat{\pi}_{t+1}^{\omega}-\frac{\Pi_{1}}{1+\varepsilon_{L} \rho_{L}}\left(\left(\hat{w}_{t}-\widehat{m r s}_{t}\right)-\rho_{L} \sigma\left(\hat{w}_{t}-\widehat{m p l}_{t}\right)\right)
$$

converges to the equilibrium payoff for the workers, $U_{u}^{t}$, since their share of the total surplus must go to zero. This, in turn, implies that wages are determined by the constraints and the firm's preferred wage is determined by $U_{u}^{t}=U_{o}$ (see the Technical Appendix for details).

${ }^{11}$ Here, the direct effects working through effects on consumption and leisure cancel through efficiency, and only the indirect effect via the effect on marginal costs and prices and its effect on labor demand remain (see the Technical Appendix for details). 
The only difference is then that the $\hat{w}_{t}-\widehat{m p l}_{t}$ also enters the expression. The reason for the presence of this term is that when $\hat{w}_{t}>\widehat{m p l}_{t}$, marginal costs are high in the economy. A reduction in wages then leads to an increase in surplus for those who reset wages. The more intense the competition, captured by $\sigma$, the larger the effect on wages. In the Erceg, Henderson, and Levin (2000) model, on the other hand, the wage set by a single household does not affect the marginal costs of firms since each firm uses labor from a continuum of households.

The reason why (23) is different from (25) when $\varphi=1$ is that we cannot set taxes to eliminate the markup in wage setting for $\varphi<1$. Doing so would lead to inconsistencies. To see this, note that when setting taxes as in Erceg, Henderson, and Levin (2000), the steady state first-order condition for wage setting (15) becomes

$$
\varphi \bar{U}_{f}\left(u_{C}(\bar{C}) \bar{w}-v_{L}(\bar{L})\right)+(1-\varphi)\left(\bar{U}_{u}-\bar{U}_{o}\right) \frac{\partial \bar{U}_{f}}{\partial W(f)}=0
$$

By efficiency, the marginal rate of substitution is equal to the marginal product and thus, $u_{C}(\bar{C}) \bar{w}=$

$v_{L}(\bar{L})$. Hence, since $\bar{U}_{f}$ and $\frac{\partial \bar{U}_{f}}{\partial W(f)}$ are bounded away from zero, the worker steady-state surplus must be equal to zero. However, for a shock with an adverse effect on the surplus, we end up in situations where $U_{u}^{t}<U_{o}$, which lead to inconsistencies. Here instead, we adjust the threat point so that the share of the surplus obtained by the firms is always $1-\varphi$. Then, by construction, we will have $\tau_{w}=0$. Taking this approach then yields the wage-setting curve (23).

\section{Welfare}

Following the main part of the monetary policy literature, we focus on the limiting cashless economy (see e.g. Woodford (2003) for a discussion) with the social welfare function

$$
E_{t} \sum_{t=0}^{\infty} \beta^{t}\left(u\left(C_{t}\right)-\int_{0}^{1} v\left(L_{t}(f)\right) d f\right) .
$$

Following Rotemberg and Woodford (1997), Erceg, Henderson, and Levin (2000) and others, we take a second-order approximation to (27) around the steady state. This yields a standard expression for the welfare gap (see the Technical Appendix for a detailed derivation, also c.f. Erceg, Henderson, and Levin (2000)), i.e., the discounted sum of log-deviations of welfare from the natural (flexible price and wage welfare level)

$$
E_{t} \sum_{t=0}^{\infty} \beta^{t}\left(\theta_{x}\left(\hat{x}_{t}\right)^{2}+\theta_{\pi}\left(\hat{\pi}_{t}\right)^{2}+\theta_{\pi^{\omega}}\left(\hat{\pi}_{t}^{\omega}\right)^{2}\right)
$$


where we have omitted higher order terms and terms independent of policy and as usual $\theta_{x}<0$, $\theta_{\pi}<0$ and $\theta_{\pi^{\omega}}<0$ (see Appendix B for definitions). The first term captures the welfare loss (relative to the flexible price and wage equilibrium) from output gap fluctuations stemming from the fact that $\widehat{m p l}$ will differ from $\widehat{m r s}$ whenever $\hat{x}_{t} \neq 0$. However, even if $\hat{x}_{t}=0$, there will be welfare losses due to nominal rigidities. The reason is that nominal rigidities imply a non-degenerate distribution of prices and wages. A non-degenerate distribution of prices and wages implies a non-degenerate distribution of output across firms and working hours across households. This leads to welfare losses due to decreasing returns to scale and increasing marginal disutility of labor.

\section{Monetary Policy}

To close the model and describe the dynamic equilibrium of the model, we need to specify monetary policy behavior. A natural starting point for an application of the model is to impose a commonly used empirical characterization of actual monetary policy in the form of a Taylor rule for interest rate setting (see Taylor (1993)). The behavior of the economy when governed by a Taylor rule is then contrasted to the behavior of the economy when governed by optimal monetary policy where the central bank aims at maximizing social welfare. Here, we focus on the discretionary case. Although studying optimal policy is essentially a normative enterprise, the focus here is natural since no central bank formally commits to a policy rule.

\subsection{A simple instrument rule}

The Taylor (1993) rule is specified as

$$
\widehat{i}_{t}=1.24 \hat{\pi}_{t}+0.33 \hat{x}_{t}
$$

where the parameters for (29) are taken from the estimates presented in Rudebusch (2002) for U.S. data (1987:Q4-1999:Q4). To close the general equilibrium system (16), (17), (18) and (21), we eliminate the nominal interest from the Euler equation (16) using the Taylor rule (29) and the real interest rate from the same expression using the corresponding flexible-price Euler equation. This condition, together with the three constraints (17) to (21), describes the dynamic equilibrium of the model under the Taylor rule.

\subsection{Optimal discretionary policy}

Under an optimal monetary policy regime, the central bank is assumed to maximize social welfare. Note that welfare only depends on the paths of $\hat{x}_{t}, \hat{\pi}_{t}$ and $\hat{\pi}_{t}^{\omega}$. Moreover, these three variables can 
solely be determined from equations (17), (18) and (21). ${ }^{12}$

To find the optimal rule under discretion, the central bank solves the following problem

$$
V\left(\hat{w}_{t-1}, \hat{w}_{t}^{*}\right)=\max _{\left\{\hat{x}_{t}, \hat{\pi}_{t}, \hat{\pi}_{t}^{\omega}, \hat{w}_{t}\right\}} \theta_{x}\left(\hat{x}_{t}\right)^{2}+\theta_{\pi}\left(\hat{\pi}_{t}\right)^{2}+\theta_{\pi^{\omega}}\left(\hat{\pi}_{t}^{\omega}\right)^{2}+\beta E_{t} V\left(\hat{w}_{t}, \hat{w}_{t+1}^{*}\right)
$$

subject to equations (17)-(21). We restrict the attention to Markov-perfect equilibria, i.e., we do not consider any equilibria with reputational effects that could arise from complex non-Markov behavior. However, we need to take into account that the real wage is an endogenous state variable. Therefore, expected inflation and expected wage inflation will depend on lagged real wages in equilibrium. An implication of this is that when designing monetary policy, even in the absence of a commitment mechanism, the central bank should take into account how changes in the real wage today affect private sector expectations.

Note that we solve the problem in a different way than Erceg, Henderson, and Levin (2000). Instead of postulating the form of the interest rate rule and then choosing parameters to maximize welfare, we find the paths for $\hat{x}_{t}, \hat{\pi}_{t}, \hat{\pi}_{t}^{\omega}$ and $\hat{w}_{t}$ that maximize welfare, as suggested by Woodford (2003).

The first-order conditions for optimal discretionary monetary policy are

$$
\begin{aligned}
0 & =2 \theta_{x} \hat{x}_{t}-\lambda_{t}^{\pi} \frac{\gamma}{1-\gamma} \Pi+\lambda_{t}^{\pi^{\omega}} \Omega_{x}, \\
0 & =2 \theta_{\pi} \hat{\pi}_{t}+\lambda_{t}^{\pi}+\lambda_{t}^{w}, \\
0 & =2 \theta_{\pi^{\omega}} \hat{\pi}_{t}^{\omega}-\lambda_{t}^{\pi}(1-\gamma)-\lambda_{t}^{w}+\lambda_{t}^{\pi^{\omega}}, \\
0 & =\beta E_{t} V_{1}\left(\hat{w}_{t}, \hat{w}_{t+1}^{*}\right)-\lambda_{t}^{\pi}\left(\beta E_{t} \frac{\partial \hat{\pi}_{t+1}}{\partial \hat{w}_{t}}-(1-\gamma) \beta E_{t} \frac{\partial \hat{\pi}_{t+1}^{\omega}}{\partial \hat{w}_{t}}+\Pi\right)+\lambda_{t}^{w}-\lambda_{t}^{\pi^{\omega}}\left(\beta E_{t} \frac{\partial \hat{\pi}_{t+1}^{\omega}}{\partial \hat{w}_{t}}-\Omega_{w}\right),
\end{aligned}
$$

where $\lambda_{t}^{\pi}, \lambda_{t}^{w}$ and $\lambda_{t}^{\pi^{\omega}}$ denote the Lagrange multipliers.

The problem can be reduced by using the first three first-order conditions to solve for the Lagrange multipliers and then substituting these into the last first-order condition. This condition, together with the three constraints (17) to (21) then describe the dynamic equilibrium of the model under optimal discretionary policy (see the Technical Appendix for details).

\section{Calibration and Numerical Solution}

As in Erceg, Henderson, and Levin (2000), we only focus on a technology shock in our application, which is assumed to follow an $\operatorname{AR}(1)$. It is straightforward to show that there is a positive linear

\footnotetext{
${ }^{12}$ To solve for the equilibrium nominal interest rate response, the solution for $\hat{\pi}_{t}, \hat{\pi}_{t}^{\omega}$ and $\hat{x}_{t}$ can be used together with the Euler equation (16).
} 
relationship between $\hat{w}_{t}^{*}$ and $\hat{A}_{t}$. Then, if technology follows an $\operatorname{AR}(1)$ process, $\hat{w}_{t}^{*}$ also follows an $\operatorname{AR}(1)$ process. We can thus model $\hat{w}_{t}^{*}$ as

$$
\hat{w}_{t}^{*}=\eta \hat{w}_{t-1}^{*}+\varepsilon_{t}
$$

where $\varepsilon_{t}$ is an (scaled) i.i.d. (technology) shock with standard deviation $\sigma_{\epsilon}$.

For our numerical exercises, we follow Erceg, Henderson, and Levin (2000) and assume that

$$
u\left(C_{t}\right)=\frac{1}{1-\chi_{C}}\left(C_{t}-\bar{Q}\right)^{1-\chi_{C}}
$$

and that

$$
v\left(L_{t}\right)=-\frac{1}{1-\chi_{L}}\left(1-L_{t}-\bar{Z}\right)^{1-\chi_{n}}
$$

Here, we introduce $\bar{Q}$ and $\bar{Z}$ in order to facilitate the comparison with Erceg, Henderson, and Levin (2000) by mimicking the preferences and the steady state of their model. ${ }^{13}$ The calibration of the deep parameters, presented in Table 1, also follows Erceg, Henderson, and Levin (2000) when possible (thus, e.g., we do not follow Erceg, Henderson, and Levin (2000) when calibrating $\alpha$ and $\alpha_{w}$, since they have a different interpretation in our model).

\begin{tabular}{llll}
\multicolumn{3}{c}{ Table 1: Baseline Calibration of the Model } \\
\hline \multicolumn{2}{c}{ Deep Parameters } & \multicolumn{3}{l}{ Derived Parameters } \\
\hline$\alpha$ & $2 / 3$ & $\Pi$ & 0.5050 \\
$\alpha_{w}$ & $3 / 4$ & $\Pi_{1}$ & 0.08583 \\
$\beta$ & 0.99 & $\Omega_{w}$ & 0.1077 \\
$\gamma$ & 0.30 & $\Omega_{x}$ & 0.004464 \\
$\chi_{C}$ & 1.5 & $\rho_{C}$ & 1.6667 \\
$\chi_{n}$ & 1.5 & $\rho_{L}$ & -0.5786 \\
$\sigma$ & 4 & $\theta_{x}$ & -0.9621 \\
$\varphi$ & 0.5 & $\theta_{\pi}$ & -1.8258 \\
$\eta$ & 0.95 & $\theta_{\pi} \omega$ & -9.1223 \\
$\sigma_{\epsilon}$ & 0.0067 & & \\
\hline \hline
\end{tabular}

Moreover, to find the steady state of the model, we also follow Erceg, Henderson, and Levin (2000) and set; $\bar{Q}=0.3163, \bar{Z}=0.03, \bar{K}=30 \bar{Q}$ and $\bar{A}=4.0266$. Then, using the scheme outlined in section (2.4) we obtain $\bar{L}=0.27$. Thus, $\bar{L}$ and $\bar{Z}$ stand for about one third of the household's time endowment. Also, $\bar{Y}=\bar{C}=3.1627$, giving rise to a steady state capital-output ratio of about three. Moreover, to achieve symmetric Nash bargaining (equally shared surplus) in the baseline scenario, we set $\varphi$ to 0.5.

Letting $d_{p}$ and $d_{w}$ denote the duration of price and wage contracts, respectively, we have $d_{p}=$

\footnotetext{
${ }^{13}$ In the Technical Appendix, where we allow for consumption and labor supply shocks, $\bar{Q}$ corresponds to the steady state value of a consumption shock and $\bar{Z}$ to the steady state value of a labor-supply shock.
} 
$1 /\left(1-\alpha_{w} \alpha\right)$ and $d_{w}=1 /\left(1-\alpha_{w}\right)$. Starting with wage contract duration, Taylor (1999) summarizes the evidence and argues that overall, the evidence points toward a wage contract duration of about one year. This, in turn, implies that we set $\alpha_{w}=3 / 4$. For price contract duration, the micro evidence presented by Bils and Klenow (2004) suggests a price duration of about five months, whereas the survey evidence in Blinder, Canetti, Lebow, and Rudd (1998) suggests about eight months. In our baseline calibration, we set the price duration to two quarters, which is about the average for the above studies. This, in turn, implies that we set $\alpha=2 / 3$.

In table 1 , note the high weight on wage inflation variance in the loss function. This is in part due to wages being stickier than prices.

To obtain a ball-park estimate of $\sigma_{\epsilon}$, we make use of Rudebusch (2002) Taylor rule estimates as an approximation of actual monetary policy and set $\sigma_{\epsilon}$ to match the standard deviation of quarterly inflation in the model under a Taylor rule imposed with the actual standard deviation of the U.S. quarterly CPI inflation in the same sample as that used by Rudebusch (2002). ${ }^{14}$ This results in a standard deviation of the innovation to the $\hat{w}_{t}^{*}$ process of $0.0067\left(=\sigma_{\epsilon}\right)$.

Note that we cannot put the system under optimal discretionary policy, discussed in section 5.2, on standard form (as outlined in e.g. Blanchard and Kahn (1980)). The reason for this is that expectations depend on real wages which, in turn, is a state variable that depends on policy. This gives rise to the three derivatives of the expectations in the last equation in (31). To solve the problem, we then rely on a value-function iteration procedure. Within each iteration, we solve the system in section 5.2 for the policy functions, while taking into account how expectations in the constraints are affected. After obtaining a new guess for the policy functions, we update the value function using this new guess and iterate until the value function converges (the details are outlined in Appendix A). For the system under a Taylor rule, discussed in section 5.1, there is no need to iterate on the value function since no derivatives of future inflation are present in (29). Instead, we can directly solve the system in section 5.1 for the policy functions (i.e. we only do step 1 in the numerical algorithm outlined in Appendix A). ${ }^{15}$

\section{$7 \quad$ Results}

We first plot impulse responses in the two cases (Taylor rule/optimal discretionary policy) for our baseline calibration above. Then, we turn to the welfare effects of labor-market institutions, studying the effects of varying the relative bargaining power of the household and to what extent monetary

\footnotetext{
${ }^{14}$ We focus on inflation for the calibration, since this is the only variable we can directly observe without resorting to some filtering technique.

${ }^{15}$ Here, standard methods can thus be applied and when comparing methods, we arrive at the same policy functions.
} 
policy can affect the dynamic outcome.

\subsection{Impulse responses}

In Figure 1, we plot the impulse response to a one standard deviation innovation to the natural real wage $\hat{w}_{t}^{*}$ when monetary policy is governed by the Taylor rule estimated by Rudebusch (2002).

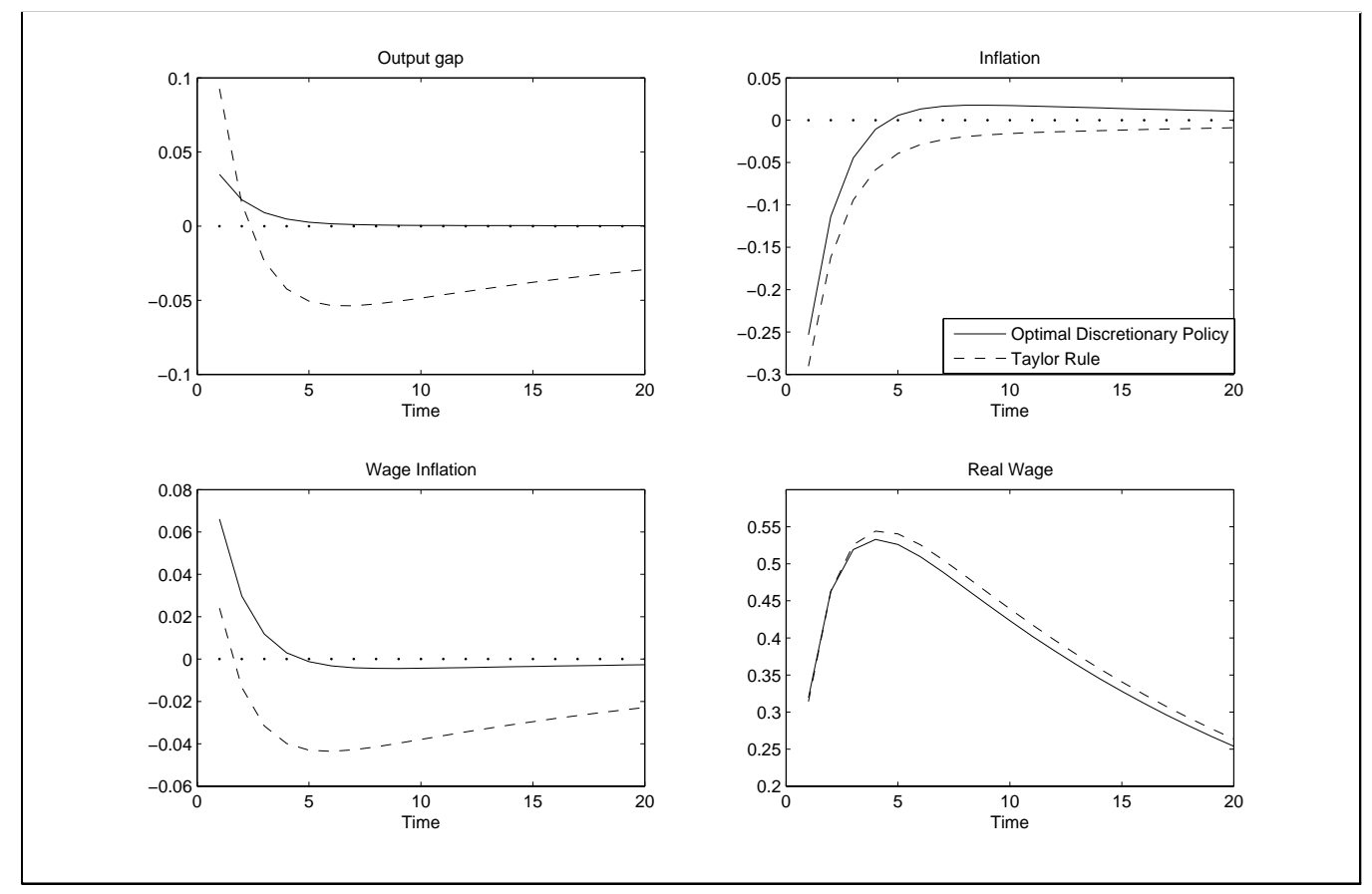

Figure 1: Impulse responses to a one-standard deviation innovation to $\hat{w}_{t}^{*}$ when the nominal interest rate is governed by Optimal Discretionary Policy and the Empirical Taylor Rule, respectively.

The shock initially drives up the natural real wage by 0.67 percent and thus, causes a negative real wage gap. To close the gap and stabilize the economy, the central bank needs to increase the real wage. This is achieved by keeping inflation lower than wage inflation and is also what the empirical Taylor rule implies. However, given the $\operatorname{AR}(1)$ structure of the shock, the natural real wage falls down towards the steady value of zero after the initial shock. So at some point, the central bank needs to start to reduce the real wage in order to continue to stabilize the economy. This is also what we see after approximately four quarters. For this purpose, the relation between wage inflation and inflation $\left(\hat{\pi}_{t}^{\omega}-\hat{\pi}_{t}\right)$ needs to be reversed, which also happens at this point in time. The economy is then stabilized and eventually tends towards the steady state.

In Figure 1, we also plot the impulse response to a one standard deviation innovation to the natural real wage $\hat{w}_{t}^{*}$ under optimal discretionary monetary policy. The main difference relative to the behavior of the economy under a Taylor rule is that the economy is stabilized much faster and that inflation and wage inflation shift signs (approximately) simultaneously, as expected by optimal 
policy. This indicates that the welfare loss under the optimal discretionary policy is lower than under the Taylor rule. Note that the latter result is not trivial, since the Taylor rule is in fact a commitment rule and hence, could theoretically perform better than the optimal discretionary rule.

In Figure 2, we compare the impulse responses from our model under optimal discretionary monetary policy when the union has all bargaining power (i.e., $\varphi=1$ ) to the impulse responses from the Erceg, Henderson, and Levin (2000) model. The main differences are that wage inflation is used more heavily to stabilize the economy in our model, and less so for inflation and the output gap. When it comes to the qualitative features of the impulse responses, they are similar for the two models, however. There are two potential sources for the quantitative differences that we see in figure 2. First, the coefficients in the welfare function (28) are different in the two models and, second, private-sector behavior as described by (16)-(21) in our model, is also different. To check which of these two effects that is the main cause for the differences in Figure 2, we imposed the welfare function coefficients from our model on the Erceg, Henderson, and Levin (2000) model. Then, the differences between the two models remain, implying that the main cause of the discrepancies in the figure is differences in private sector behavior (i.e. in price and wage-setting relations).

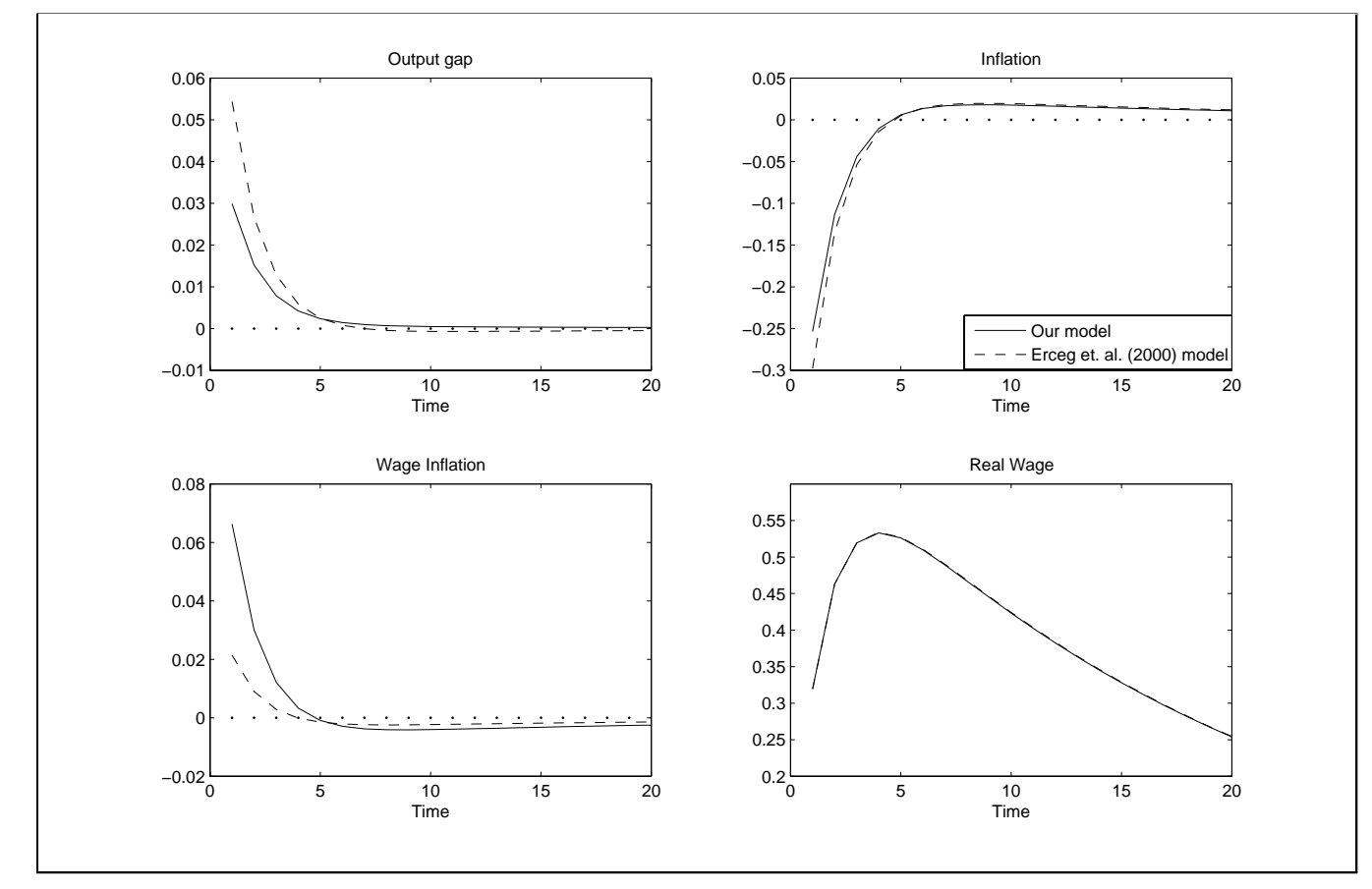

Figure 2: Impulse responses to a one-standard deviation innovation to $\hat{w}_{t}^{*}$ when the nominal interest rate is governed by Optimal Discretionary Policy in our and the Erceg et al. (2000) model, respectively. 


\subsection{Welfare and labor-market institutions}

Labor-market institutions are complex to model. However, e.g. changes in legislation that strengthen unions can reasonably be modelled as an increase in their bargaining power in negotiations. Therefore, we focus on how changes in bargaining power affect the welfare loss and how this welfare loss interacts with monetary policy choices.

In Figure 3, we plot the welfare differences (relative to the natural welfare level) for different values of the relative bargaining power of the union under the Taylor rule and under optimal discretionary policy. To compute welfare, we construct sequences of shocks for 1000 periods and use these to find paths for the variables $\hat{x}_{t}, \hat{\pi}_{t}, \hat{\pi}_{t}^{\omega}$ and $\hat{w}_{t}$. Then, welfare is computed from these paths using the welfare criterion (28), ignoring the periods $t>1000$. This is repeated 1000 times to generate an approximation of the expectation. Finally, to express the welfare loss as a fraction of steady-state consumption we scale the welfare difference $(28)$ by $u_{C}(\bar{C}) \bar{C}$. When monetary policy is governed by the Taylor rule, outlined above, we see that the welfare loss is increasing in the relative bargaining power of the union. The reason for this result is that the stronger is the union in the bargaining process, the larger are

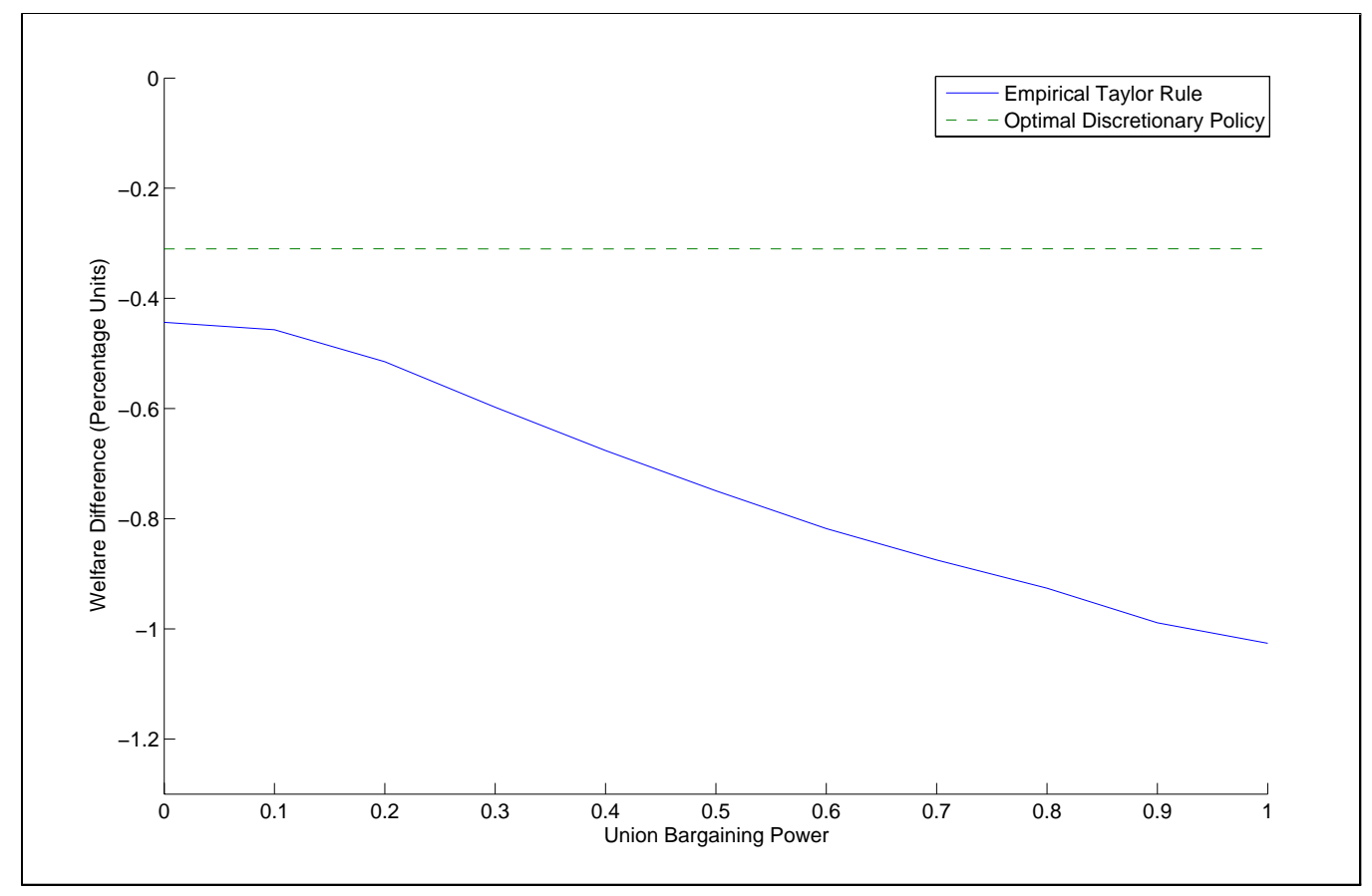

Figure 3: Welfare differences (from the natural level) in percentage units of steady state consumption for different values of the union's relative bargaining power.

the effects on wage outcomes from changes in the total surplus, since an increase in the total surplus in the negotiation leads to a larger wage increase when the union has more bargaining power. ${ }^{16}$ Thus,

\footnotetext{
${ }^{16}$ Since all surplus is transferred to households either via wages or dividends from firms, this implies that transfers
} 
the more will wages fluctuate in response to disturbances, and since variation in wage-inflation rates depresses welfare, we get the pattern present in figure 3 . However, as can also be seen in figure 3 , this effect on the responsiveness of wages can be (almost) completely counteracted by monetary policy.

It is also interesting to note that the effects on welfare differences are sizable. For example, for the case when $\varphi=1$, we have that the differences between optimal discretionary and the Taylor policy are about 0.7 percent of steady state consumption.

The findings in this section are qualitatively robust to a wide variety of experiments. For example, using the original Taylor (1993) parameters in the Taylor rule (i.e., $\beta_{\hat{\pi}}=1.5, \beta_{\hat{x}}=0.5$ ), increasing the duration of wage and price contracts by setting $d_{p}=3, d_{w}=6$, tending towards log utility in preferences (i.e., setting $\chi_{C}=\chi_{L}=1.001$ ), or increasing (decreasing) the markup rate by setting $\sigma$ to 3 (6) does not change the overall picture that welfare is falling with the bargaining power of the union under the Taylor rule, and that this effect can be neutralized under optimal discretionary monetary policy.

\section{Concluding Remarks}

In this paper, we outline a model with both staggered prices and wages where wages are bargained over between firms and unions. Based on empirical evidence, we introduce a modification of price and wage setting behavior in the standard Calvo framework. Specifically, we allow prices to be changed whenever wages are. This assumption greatly simplifies the analysis of the problem. In particular, complicated interdependencies between current and future price and wage decisions that would be present in the standard Calvo framework are eliminated. This gives rise to a simple but more realistic representation of the labor market that can be used as a building block in a much richer DSGE model than presented here.

In an application we use the model to investigate the interaction between monetary policy and labor-market institutions. When central bank behavior is captured by a Taylor rule, welfare decreases substantially as the relative union bargaining power increases. The reason for this result is that the stronger is the union in the bargaining process, the larger are the effects on wage outcomes from changes in the total surplus, since an increase in the total surplus in the negotiation leads to a larger wage increase, and hence larger wage inflation variability, when the union has more bargaining power. Thus, the more will wage inflation fluctuate in response to disturbances, leading to a decrease in welfare. However, under optimal discretionary policy, this effect is almost neutralized and welfare is independent of union bargaining power.

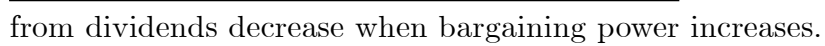


In the paper, we model bargaining in a simple way. More complicated models of the labor market like the search model presented in Gertler and Trigari (2006) or insider-outsider models, see e.g., Blanchard and Summers (1986) and Gottfries and Horn (1987), can be adapted to the framework in the paper, which provides an interesting avenue for future research. 


\section{References}

Adolfson, M., S. Laséen, J. Lindé, and M. Villani (2005). Bayesian estimation of an open economy dsge model with incomplete pass-through, Sveriges Riksbank Working Paper No. 179.

Altissimo, F., M. Ehrmann, and F. Smets (2006, June). Inflation persistence and price-setting in the euro area. Occasional paper series no 46, ECB.

Barro, R. and D. Gordon (1983a). A positive theory of monetary policy in a natural rate model. Journal of Political Economy 91, 589-610.

Barro, R. and D. Gordon (1983b). Rules, discretion and reputation in a model of monetary policy. Journal of Monetary Economics 12, 101-121.

Bils, M. and P. Klenow (2004). Some evidence on the importance of sticky prices. Journal of Political Economy 112, 947-985.

Binmore, K., A. Rubinstein, and A. Wolinsky (1986). The nash bargaining solution in economic modelling. RAND Journal of Economics 17, 176-188.

Blanchard, O. and C. Kahn (1980). The solution of linear difference models under rational expectations. Econometrica 48, 1305-1312.

Blanchard, O. and L. Summers (1986). Hysteresis and the european unemployment problem. In S. Fischer (Ed.), NBER Macroeconomics Annual, Volume 1, pp. 15-78. MIT Press.

Blinder, A., E. Canetti, D. Lebow, and J. Rudd (1998). Asking About Prices: A New Approach to Understand Price Stickines. New York: Russel Sage Foundation.

Calmfors, L. (2001). Unemployment, labor market reform and monetary union. Journal of Labor Economics 19, 265-289.

Calvo, G. (1983). Staggered prices in a utility-maximizing framework. Journal of Monetary Economics 12, 383-398.

Carlsson, M. and A. Westermark (2006). Technical appendix to optimal discretionary monetary policy under downward nominal wage rigidity, Mimeo, Uppsala University, Department of Economics.

Christiano, L., M. Eichenbaum, and C. Evans (2005, February). Nominal rigidities and the dynamic effects of a shock to monetary policy. Journal of Political Economy 113(1), 1-45.

Erceg, C., D. Henderson, and A. Levin (2000). Optimal monetary policy with staggered wage and price contracts. Journal of Monetary Economics 46, 281-313. 
Gertler, M. and A. Trigari (2006). Unemployment fluctuations with staggered nash wage bargaining, NBER Working Papers 12498.

Gottfries, N. and H. Horn (1987, dec). Wage formation and the persistence of unemployment. Economic Journal 97(388), 877-884.

Judd, K. L. (1998). Numerical Methods in Economics. Cambridge, MA: MIT Press.

Mortensen, D. (2005). Growth, unemployment, and labor market policy. Journal of the European Economic Association 3, 236-258.

Osborne, M. and A. Rubinstein (1990). Bargaining and Markets. San Diego, CA: Academic Press.

Rotemberg, J. and M. Woodford (1997). An optimization-based econometric framework for the evaluation of monetary policy. In B. Bernanke and J. Rotemberg (Eds.), NBER Macroeconomics Annual. Cambridge, MA: MIT Press.

Rubinstein, A. (1982). Perfect equilibrium in a bargaining model. Econometrica 50, 97-109.

Rudebusch, G. (2002). Term structure evidence on interest rate smoothing and monetary policy inertia. Journal of Monetary Economics 49, 1161-1187.

Smets, F. and R. Wouters (2003, Sept). An estimated dynamic stochastic general equilibrium model of the euro area. Journal of the European Economic Association 1(5), 1123-1175.

Taylor, J. (1993). Discretion versus policy rules in practice. Carnegie-Rochester Conference Series on Public Policy 39, 195-214.

Taylor, J. (1999). Staggered price and wage setting in macroeconomics. In J. Taylor and M. Woodford (Eds.), Handbook of Macroeconomics, Volume 1B. Elsevier, Amsterdam.

Woodford, M. (2003). Interest and Prices: Foundations of a Theory of Monetary Policy. Princeton, NJ: Princeton University Press. 


\section{Appendix}

\section{A Numerical algorithm}

The main outline of the algorithm follows algorithm $12.2 \mathrm{in} \mathrm{Judd} \mathrm{(1998).} \mathrm{We} \mathrm{first} \mathrm{define} N \subset R^{2}$ nodes over the state space.

Step 0. Guess policy functions $U_{i}^{0}$, i.e., parameter values in linear functions

$$
\begin{aligned}
& \hat{\pi}^{0}\left(\hat{w}_{t-1}, \hat{w}_{t}^{*}\right), \\
& \hat{\pi}^{\omega 0}\left(\hat{w}_{t-1}, \hat{w}_{t}^{*}\right), \\
& \hat{x}^{0}\left(\hat{w}_{t-1}, \hat{w}_{t}^{*}\right),
\end{aligned}
$$

and value function

$$
V^{0}\left(\hat{w}_{t-1}, \hat{w}_{t}^{*}\right)
$$

Then proceed to step 2 .

Step 1.

Consider the system derived by using the first three first-order conditions in (31) to eliminate the Lagrange multipliers in the last first-order condition, together with the three constraints (17) to (21) (see the discussion in section 5.2 and the Technical Appendix)

$$
\begin{aligned}
0= & \beta E_{t} V_{1}\left(\hat{w}_{t}, \hat{w}_{t+1}^{*}\right)-\lambda_{t}^{\pi}\left(\hat{x}_{t}, \hat{\pi}_{t}, \hat{\pi}_{t}^{\omega}\right)\left(\beta E_{t} \frac{\partial \hat{\pi}_{t+1}}{\partial \hat{w}_{t}}-(1-\gamma) \beta E_{t} \frac{\partial \hat{\pi}_{t+1}^{\omega}}{\partial \hat{w}_{t}}+\Pi\right) \\
& +\lambda_{t}^{w}\left(\hat{x}_{t}, \hat{\pi}_{t}, \hat{\pi}_{t}^{\omega}\right)-\lambda_{t}^{\pi^{\omega}}\left(\hat{x}_{t}, \hat{\pi}_{t}, \hat{\pi}_{t}^{\omega}\right)\left(\beta E_{t} \frac{\partial \hat{\pi}_{t+1}^{\omega}}{\partial \hat{w}_{t}}-\Omega_{w}\right), \\
\hat{\pi}_{t}= & \beta E_{t} \hat{\pi}_{t+1}+(1-\gamma)\left(\hat{\pi}_{t}^{\omega}-\beta E_{t} \hat{\pi}_{t+1}^{\omega}\right)+\Pi\left(\hat{w}_{t}-\hat{w}_{t}^{*}\right)+\frac{\gamma}{1-\gamma} \Pi \hat{x}_{t}, \\
\hat{w}_{t}= & \hat{w}_{t-1}+\hat{\pi}_{t}^{\omega}-\hat{\pi}_{t}, \\
\hat{\pi}_{t}^{\omega}= & \beta E_{t} \hat{\pi}_{t+1}^{\omega}-\Omega_{x} \hat{x}_{t}-\Omega_{w}\left(\hat{w}_{t}-\hat{w}_{t}^{*}\right) .
\end{aligned}
$$

In addition, we use the envelope theorem to eliminate $E_{t} V_{1}\left(\hat{w}_{t}, \hat{w}_{t+1}^{*}\right) .{ }^{17}$

We find the new guess for the policy functions $U_{i}^{l+1}$ by solving for these from system (37), with a collocation method. While solving for policy functions, we take into account that the policy functions affect the expectations.

Step 2. Compute current period utility $P_{i}^{l+1}$ for $i=1, \ldots, N$, given policy function guesses $U_{i}^{l+1} \cdot{ }^{18}$

\footnotetext{
${ }^{17}$ From the envelope theorem, we have$$
E_{t} V_{1}\left(\hat{w}_{t}, \hat{w}_{t+1}^{*}\right)=-E_{t} \lambda_{t+1}^{w} .
$$

${ }^{18}$ In terms of Judd (1998) p. 416, compute $\pi\left(y_{i}, U_{i}^{l+1}\right)$ where $U_{i}^{l+1}$ consists of $\hat{\pi}_{t}, \hat{\pi}_{t}^{\omega}$ and $\hat{x}_{t}$ and $y_{i}=\left(\hat{w}_{t-1}, \hat{w}_{t}^{*}\right)_{i}$, 
Step 3. Update the value function $V^{l+1}\left(\hat{w}_{t-1}, \hat{w}_{t}^{*}\right)$ using

$$
V^{l+1}=\left(I-\beta Q^{U^{l+1}}\right)^{-1} P^{l+1}
$$

where $Q^{U^{l+1}}$ is the transition matrix defined by the new guess for the policy functions for inflation and wage inflation and the flow equation for real wages.

Step 4. If $\left\|V^{l+1}-V^{l}\right\|<\varepsilon$ stop. Otherwise, go to step 1 .

\section{B Derived Parameters}

In the Technical Appendix, we derive the following parameter for the wage setting Phillips curve (21)

$$
\begin{aligned}
& \Omega_{x}=\frac{\varphi\left(\frac{1-\sigma \gamma}{1-\gamma} \frac{1+\rho_{L} \varepsilon_{L}}{1+\varepsilon_{L}}-\rho_{C}\right)+(1-\varphi) \sigma \frac{\gamma}{1-\gamma}}{\varphi\left(\frac{\varepsilon_{L}}{1+\varepsilon_{L}}\left(1+\rho_{L} \varepsilon_{L}\right)+1\right)-(1-\varphi) \varepsilon_{L}}, \\
& \Omega_{w}=\frac{\varphi\left(\frac{\varepsilon_{L}}{1+\varepsilon_{L}}\left(1-\sigma \rho_{L}\right)+\frac{1}{1-\gamma}\right)+(1-\varphi) \sigma}{\varphi\left(\frac{\varepsilon_{L}}{1+\varepsilon_{L}}\left(1+\rho_{L} \varepsilon_{L}\right)+1\right)-(1-\varphi) \varepsilon_{L}} .
\end{aligned}
$$

We also derive the following parameters for the welfare gap expression (28)

$$
\begin{aligned}
\theta_{x} & =\frac{\bar{C}}{2} \bar{u}_{C}\left(-\rho_{C}+\rho_{L} \frac{1}{1-\gamma}-\frac{\gamma}{1-\gamma}\right), \\
\theta_{\pi} & =-\frac{\bar{v}_{L} \bar{L}}{2} \sigma \frac{1}{\Pi}, \\
\theta_{\pi^{\omega}} & =-\frac{\bar{v}_{L} \bar{L}}{2}\left(\left(-\gamma \varepsilon_{L}+\sigma(1-\gamma)\right) \frac{1}{\Pi_{1}}-\sigma(1-\gamma)^{2} \frac{1}{\Pi}\right) .
\end{aligned}
$$

In the Technical Appendix, we also show that in an Erceg, Henderson, and Levin (2000) economy we need to replace $\theta_{\pi^{\omega}}$ with

$$
\theta_{\pi^{\omega}}^{E H L}=-\frac{\bar{v}_{L} \bar{L}}{2} \sigma_{w} \frac{1}{\Pi_{1}}
$$

where $\sigma_{w}$ governs the substitutability between workers (note that our parameter $\sigma_{w}$ corresponds to $\left(1+\theta_{w}\right) / \theta_{w}$ in the notation of Erceg, Henderson, and Levin (2000)). Note that we derive the welfare gap in a slightly different way (see the Technical Appendix for details) and therefore (42) is different than in Erceg, Henderson, and Levin (2000). ${ }^{19}$ Note that the wage-setting relationship in an Erceg, Henderson, and Levin (2000) economy is given by (24) and the price-setting relationship is given by (17), but without the $(1-\gamma)\left(\hat{\pi}_{t}^{\omega}-\beta E_{t} \hat{\pi}_{t+1}^{\omega}\right)$ term.

which gives $P_{i}^{l+1}=\pi\left(y_{i}, U_{i}^{l+1}\right)$

${ }^{19}$ For the same reason, $\theta_{\pi}^{E H L}\left(=\theta_{\pi}\right)$ is different from the parameter derived in Erceg, Henderson, and Levin (2000) 
WORKING PAPERS*

Editor: Nils Gottfries

2006:1 Jie Chen, The Dynamics of Housing Allowance Claims in Sweden: A discrete-time hazard analysis. 37pp.

2006:2 Fredrik Johansson and Anders Klevmarken: Explaining the size and nature of response in a survey on health status and economic standard. 25pp.

2006:3 Magnus Gustavsson and Henrik Jordahl, Inequality and Trust: Some Inequalities are More Harmful than Others. 29pp.

2006:4 N. Anders Klevmarken, The Distribution of Wealth in Sweden: Trends and Driving factors. 20pp.

2006:5 Erica Lindahl and Andreas Westermark: Soft Budget Constraints as a Risk Sharing Arrangement in an Economic Federation. 22pp.

2006:6 Jonas Björnerstedt and Andreas Westermark: Bargaining and Strategic Discrimination. 36pp.

2006:7 Mikael Carlsson, Stefan Eriksson and Nils Gottfries: Testing Theories of Job Creation: Does Supply Create Its Own Demand? 23pp.

2006:8 Annika Alexius and Erik Post, Cointegration and the stabilizing role of exchange rates. 33pp.

2006:9 David Kjellberg, Measuring Expectations. 46pp.

2006:10 Nikolay Angelov, Modellig firm mergers as a roommate problem. 21pp.

2006:11 Nikolay Angelov, Structural breaks in iron-ore prices: The impact of the 1973 oil crisis. 41pp.

2006:12 Per Engström and Bertil Holmlund, Tax Evasion and Self-Employment in a High-Tax Country: Evidence from Sweden. 16pp.

2006:13 Matias Eklöf and Daniel Hallberg, Estimating retirement behavior with special early retirement offers. 38pp.

2006:14 Daniel Hallberg, Cross-national differences in income poverty among Europe's 50+. 24pp.

2006:15 Magnus Gustavsson and Pär Österholm, Does Unemployment Hysteresis Equal Employment Hysteresis? 27pp.

2006:16 Jie Chen, Housing Wealth and Aggregate Consumption in Sweden. 52pp.

\footnotetext{
* A list of papers in this series from earlier years will be sent on request by the department.
} 
2006:17 Bertil Holmlund, Quian Liu and Oskar Nordström Skans, Mind the Gap? Estimating the Effects of Postponing Higher Education. 33pp.

2006:18 Oskar Nordström Skans, Per-Anders Edin and Bertil Holmlund, Wage Dispersion Between and Within Plants: Sweden 1985-2000. 57pp.

2006:19 Tobias Lindhe and Jan Södersten, The Equity Trap, the Cost of Capital and the Firm's Growth Path. 20pp.

2006:20 Annika Alexius and Peter Welz, Can a time-varying equilibrium real interest rate explain the excess sensitivity puzzle? 27pp.

2006:21 Erik Post, Foreign exchange market interventions as monetary policy. 34pp.

2006:22 Karin Edmark and Hanna Ågren, Identifying Strategic Interactions in Swedish Local Income Tax Policies. 36pp.

2006:23 Martin Ågren, Does Oil Price Uncertainty Transmit to Stock Markets? 29pp.

2006:24 Martin Ågren, Prospect Theory and Higher Moments. 31pp.

2006:25 Matz Dahlberg, Eva Mörk, Jørn Rattsø and Hanna Ågren, Using a discontinuous grant rule to idenitfy the effect of grants on local taxes and spending. 26pp.

2006:26 Jukka Pirttiläa and Håkan Selin, How Successful is the Dual Income Tax? Evidence from the Finnish Tax Reform of 1993. 40pp.

2006:27 Henrik Jordahl and Che-Yuan Liang, Merged Municipalities, Higher Debt: On Free-riding and the Common Pool Problem in Politics. 34pp.

2006:28 Per Engström, Ann-Sofie Kolm and Che-Yuan Liang, Maternal Addiction to Parental Leave. 18pp.

2006:29 Jonas Björnerstedt and Andreas Westermark, Delay in Bargaining with Externalities. 27pp.

2006:30 Pär Österholm, Incorporating Judgement in Fan Charts. 36pp.

2006:31 Mikael Carlsson and Andreas Westermark, Monetary Policy and Staggered Wage Bargaining when Prices are Sticky. 26pp.

See also working papers published by the Office of Labour Market Policy Evaluation http://www.ifau.se/

ISSN 1653-6975 